\title{
Nuclear Engineering Enrollments and Degrees, 2011 \\ Summary Information
}

Survey Universe. The survey includes degrees granted between September 1, 2010 and August 31, 2011. Enrollment information refers to the fall term 2011. The enrollment and degree data include students majoring in nuclear engineering or in an option program equivalent to a major. Thirty-two academic programs reported having nuclear engineering programs during 2011, and data was received from all thirty-two programs. The data for two nuclear engineering programs include enrollments and degrees in health physics options that are also reported in the health physics enrollments and degrees data.

Degree Trends. Bachelor degrees increased 18\% in 2011 over 2010, matching the number of bachelor degrees in the late 1980s but $40 \%$ less than the numbers in the late 1970s. Master's degrees decreased $9 \%$ between 2010 and 2011, matching the number of master's degrees in the mid-1990s but $40 \%$ less than the numbers in the mid-1970s. Ph.D. degrees remained the same between 2010 and 2011, but about 10\% less than the numbers in the early 1990s and 35\% less than in the early 1970s.

Nuclear Engineering Degrees, 2001 - 2011

\begin{tabular}{rrrr} 
Year & B.S. & M.S. & Ph.D. \\
\hline 2011 & 524 & 277 & 113 \\
2010 & 443 & 303 & 113 \\
2009 & 395 & 233 & 87 \\
2008 & 454 & 260 & 127 \\
2007 & 413 & 227 & 89 \\
2006 & 346 & 214 & 70 \\
2005 & 268 & 171 & 74 \\
2004 & 219 & 154 & 75 \\
2003 & 166 & 132 & 78 \\
2002 & 195 & 130 & 67 \\
2001 & 120 & 145 & 80
\end{tabular}

Enrollment Trends. Undergraduate junior and senior student enrollments increased by 30\% in 2011 over 2010, continuing the upward trend reported in all but one year since 2001. Graduate student enrollments decreased by $4 \%$ in 2011 compared to 2010, the first decrease reported in 10 years.

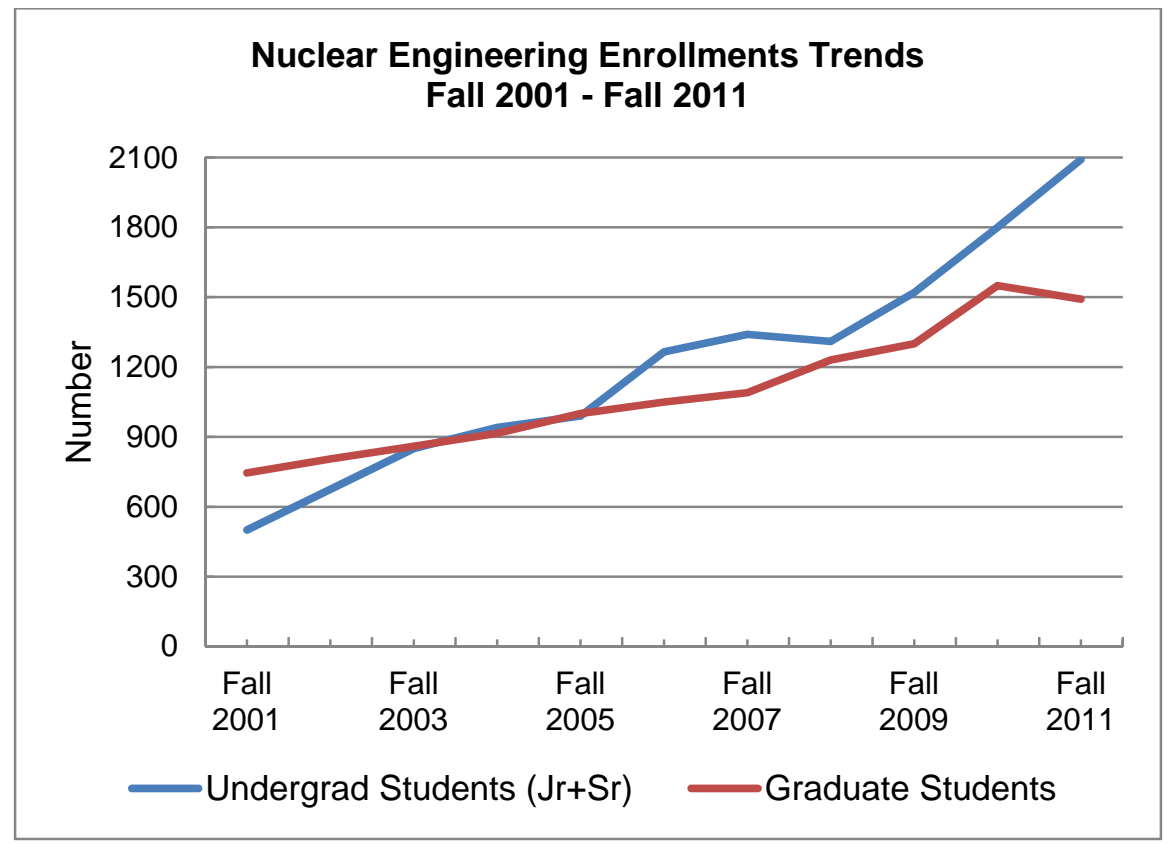

Prepared by: Analysis and Evaluation, Science Education Programs, Oak Ridge Institute for Science and Education, October 2012.

This document was prepared for the U.S. Nuclear Regulatory Commission by the Oak Ridge Institute for Science and Education (ORISE) through an interagency agreement with the U.S. Department of Energy (DOE). ORISE is managed by Oak Ridge Associated Universities under DOE contract number DE-AC05-06OR23100. 